\title{
Criteria For The Development of Green Office Standard of Thailand For Environmental Sustainability
}

\author{
Sayam Aroonsrimorakot ( $\nabla$ sayam.aro2560@gmail.com ) \\ Mahidol University https://orcid.org/0000-0002-5974-013X \\ Meena Laiphrakpam \\ Mahidol University \\ Kornkanok Sarapirom \\ Mahidol University
}

\section{Research}

Keywords: Environmental Sustainability, Green Office Standard, Criteria, Thailand

Posted Date: October 5th, 2021

DOl: https://doi.org/10.21203/rs.3.rs-910545/v1

License: (c) (i) This work is licensed under a Creative Commons Attribution 4.0 International License. Read Full License 


\section{Abstract}

The Green Office Standard was developed to lessen resource consumption and wastage in the office work process, achieve savings and minimize $\mathrm{CO}_{2}$ emission from the office's operations in the environment. Its long-term goal is training and motivating staff for resource efficiency, energy conservation, reduce pollution and wastage in the offices' work process and recycle the generated waste and these behavioral changes will lead to environmental sustainability. This research aims to develop a Green Office Standard in Thailand explaining its criteria to promote the establishment of green offices all over Thailand. Specifically, this article describes the criteria of green office standards, which are grouped into six categories as 1) Policies determination, operation planning, and continual improvement; 2) Communication and creating awareness; 3) Resource and energy consumption; 4) Office waste management; 5. Environment and safety; and 6) Eco-friendly procurement. It used mixed research methodology in different stages from March 2016 to August 2018, but mainly by the application of EDFR (Ethnographic Delphi Futures Research), by selecting a group of 17 expert panels to obtain their outlook and opinions. Green Office Standard was finally developed to certify participant-organizations in Thailand that conforms their management according to the criteria of Green Office Management Standard.

\section{Highlights}

- Green Office aims to achieve savings and minimize $\mathrm{CO}_{2}$ emission from the office's operations in the environment

- Development of the Green Office Standard will lessen resource consumption and wastage in the office work process

- Green Office Standard was developed to certify participant-organizations in Thailand that conforms their management according to the criteria of Green Office Management Standard

- The criteria for the development of Green Office Standards in Thailand are: Policies determination, operation planning, and continual improvement; Communication and creating awareness; Resource and energy consumption; Office waste management; Environment and safety; and Eco-friendly procurement

\section{Introduction}

World Wide Fund for Nature, Finland [1] first developed the Green Office Standard as an office management program with the main objective of reducing resource consumption and wastage in the office work process, achieve savings to lessen the burden of $\mathrm{CO}_{2}$ emission and carbon footprint released by office's operations in the environment. Green Office Standard offers guidelines for office management that are environmentally sustainable. It is a management system in the office which is easy to implement by training the office staff to change their behavior to be responsible for the office's resource usage. Having a certified Green Office standard has a long-term goal of resource efficiency, energy conservation, reduce pollution and wastage in the offices' work process and recycle the generated waste if applicable and these changes in the work process and behavior will achieve savings to create a healthy environment, by lessening the burden on the environment. In other words, the Green Office Standard was developed with objectives of continual improvement in the office work environment, in terms of minimizing resources and wastage, to reduce the environmental impact of daily office work operations. It is commonly seen that in the daily operation of the office works process, lots of energy, paper, ink are consumed and at the same time many wastes are generated too and all these are responsible for greenhouse gas emissions. Every organization, government, or non-government, can participate to be certified as Green Office Standard. But to be a certified Green Office Standard, such organizations and their offices should follow certain criteria guidelines in the office work operations, management, and behavior of staff, employees, stakeholders, and customers by motivating and adopting environmentally sustainable habits that conform to the standard. A qualified Green Office is provided with a Green Logo Certificate.

\subsection{Review of Literature}

DEQP (Department of Environmental Quality Promotion) is the pioneer agency that propagates and supports the importance of conservation, pollution reduction, and promotion of eco-friendly products for a healthy environment. DEQP has made many attempts with introducing and implementing projects for developing a sustainable environment in Thailand and Green Office is

Page 2/18 
one such project targeting to find a sustainable solution in the organization of the office's management since daily office operations consume a lot of energy, paper, ink, etc., and also generate much waste. So, under the sponsorship of DEQP, Aroonsrimorakot et al. [2] evaluated the Green Office Projects in Thailand in terms of social, economic, and environmental impact of these projects concerning SDGs (Sustainable Development Goals) of the United Nations. The data for the evaluation was collected through the application of questionnaires from 73 offices, along with the guidelines of multistage evaluation, monitoring, and analyzing participating offices in their daily office's work operation process and procedure for certifying as a green office standard. The evaluation result found a high satisfaction rate from the participants on national auditors, office staffs knowledge, and awareness of the benefits of green office and the office's operation procedure, purchase of equipment, lighting, air conditioning, paper, ink, printer, etc. As a result of the study, the study recommended upgrading the Green Office Standards in Thailand at the International as per the SDGs. Aroonsrimorakot et al. [3] conducted another descriptive study by reviewing available literature about the purpose and principles of green office, characteristics of green office, the procedure to establish a green office, and comparative analysis of the green offices of five countries having green offices, Singapore, Hong Kong, Finland, UK, the USA along with Thailand. The article reported that a sustainable workplace is essential for environmental sustainability and this can be achieved through the establishment of green offices for behavioral changes of the office staff and efficient management practices. Green Office Standards helps to reduce natural resource consumption in the office, promote a sustainable lifestyle through training, and providing guidelines to the office staff for enhancing environmental awareness. Careless office operation has caused environmental deterioration, and care should be taken by office staff in the selection of office procurement and for consumption, and at the same time, they should have awareness with taking responsibility to save energy and resources and reduce waste that is harmful to the environment. If wastes are generated, they should be reused or recycled and if not applicable for reusing, they should be managed and disposed of at an appropriate site and such steps will help to prevent environmental quality deterioration [4]. So, Green Office Standards was developed to change the behavioral practice of the staff to lessen human activities' impact on the environment, resulting in greenhouse gas emission, climate change, and global warming [5]. This deterioration of the environment is increased as there is increasing use of fossil fuel energy in the office's work process such as air-conditioner, lighting, printer, computer, traveling vehicles, meeting, or procurement, which increasingly emit $\mathrm{CO}_{2}$, thus leading to environmental deterioration [6]. As a safeguard, offices' should initiate some steps to ward off or lessen the effect of office activities that cause environmental problems. The Green Office Standard provides guidelines criteria to save resources, reduce energy consumption and office wastes by encouraging staff to reuse and recycle, procure ecofriendly equipment, product, or services to solve these environmental problems [3,7, 8, 9]. As a first step to encounter the impact of climate change and other environmental hazards, all established organizations should reform their office practices by adopting the green office principles and following the indicators, for the efficient management of resources used in the offices' environment [10]. Varanavicius and Navikaite [11] further highlighted the necessity of proactive environmentally friendly approaches in resource usage and activities, particularly in the office organization, for environmental sustainability and economic development in recent decades due to the global impact of environmental changes and economic crisis. An organization's office should have certain qualifications listed as guidelines criteria to be certified as Green Office. Some of the criteria include 1. Save resources used in the office such as energy, water, paper, ink; 2 . Switch to using renewable energy; 3. Minimize pollution and waste, while promoting reuse and recycle of resources; 4. Innovate and adopt design that is environmentally friendly and use green materials in the construction of buildings and so on [12, 13]. So, DEQP has developed and assessed the quality of Green Office Standard environmental management in offices of Thailand since the fiscal year 2013. In course of time, within a short span, it has expanded its establishments to many parts of Thailand and at the same time developed and upgraded the eco-friendly office, including both Governmental and Non- Governmental Organizations, Public and Private. All responsible agencies or organizations investigate greenhouse gases emission in all departments, zones, or provinces and the supply chain network and consumptions. This investigation will help in leading to a green society having sustainable production and consumption. The above review of the literature suggests that the target objective of developing the Green Office Standard is to change the behavior in the offices' work process, promote benefits of saving resources, and reduction in waste to create a sustainable society with a sustainable environment, that is, to create an eco-friendly workplace with the promotion of sustainable circular economy. Thus the development of green office standards is very important as it will motivate staff to perform office tasks for environmental sustainability through offices staff training and education, thus helping to promote office's staff's awareness about the advantages of following the Green Office Standard. Following the criteria will result in dual benefits, including the office and the environment [14]. 


\subsection{Research Objectives}

This research aims to describe the criteria-guidelines for the development of Green Office Standard in Thailand so as to bring convenience in promoting the establishment of green offices all over Thailand. The main objectives of developing green office management standard of Thailand are as follows:

- Application of Green Office Practices in office organizations for improving environmental sustainability

- To evaluate sustainable practices in the offices

- To certify the participating office for sustainable environmental awareness by training and imparting education to office staff on using energy-saving devices, renewable energy sources, reduce and recycle waste, etc.

The specific objective of this research article is to describe the working guidelines criteria of green office standards, which can be grouped into six categories:

1. Policies determination, operation planning, and continual improvement

2. Communication and creating awareness

3. Resource and energy consumption

4. Office waste management

5. Environment and safety

6. Eco-friendly procurement

\section{Research Methods}

This research used mixed research methodology in different stages during a period of two years, that is, during March 2016 August 2018, conducted mainly by the application of EDFR (Ethnographic Delphi Futures Research), which is more applicable, flexible, adapted from the Delphi method [15]. EDFR is a developing future research technique that combines both Ethnography Future Research and Delphi. The combination of these techniques helps to solve the methodological weakness of each other [16]. In ethnography, the fieldwork is usually conducted by a single researcher who lives in the field or area of study, usually for a year or more to observe, participate in a variety of aspects of a cultural group and gather detailed knowledge of the subject of investigation $[17,18,19,20,21,22]$. The Delphi method aims to get more reliable data from a panel of selected experts included in the study. The Delphi method resembles the survey technique of data collection, however, unlike using a selected sample, it selects a group of expert panels, who have in-depth knowledge of the selected subject that is going to be studied, to answer the detailed information of the investigated topic through administering a questionnaire $[23,24,25,26]$. So, the integration of these two methods is called the EDFR method and this combined technique is useful to obtain views from qualified experts without prejudice or bias of influencing opinion from peer-group pressure. Moreover, responses from the panel members were anonymous [27, 28]. According to Reid [29], using the consultative Delphi method helps to improve the validity of the research due to two factors, firstly, the experts have to identify the standards which have high logical validity and this is considered as the most applicable to those environmental experts. Secondly, after having a consensus by the expert panels, they then identified and provide consent on the needed standards. The development of the standards consists of three major stages as 1) Organizing the committee; 2) Review of previous studies and preparing the outline of the Standard, and 3) Purpose of the Standard. The first step is the selection of the group of expert panels to obtain their outlook and opinions. These expert panels comprising of seventeen members were purposively selected from various governmental and state enterprises, working in environment-related organizations, including the expert group from the Faculty of Environment and Resource Studies of Mahidol University, the Department of Environmental Quality Promotion, the Pollution Control Department, the Greenhouse Gas Management Organization (Public Organization), the Center for Nature and Agricultural Ecology, The Electricity Generating Authority of Thailand, Bangchak Corporation Public Company Limited (BCP), etc. After selection, the panelists were then informed of the aims and objectives of the research and the methodology and the procedure of the study as well as their roles and responsibilities in the research. Since the current research passes through many stages and is a long process, they were 
further requested to spare their valuable time despite their busy schedule as the nature of the study required extra commitment and consumed a lot of time for an extensive period.

\subsection{Procedures and instrumentation}

This study was undertaken to develop the Green Office Standard and guidelines criteria used measured in terms of the response from a standardized questionnaire - distribution was done during "Workshops" [30, 31, 32]. Panelists were provided instructions through email for completing the questionnaire and for attending the meeting in the workshop. Email and telephone conversations were further used for communication with the panelist during pre and post-workshop. The duration of the workshop is about one to two days, and four weeks duration as the time for processing the data and to create a final and improved checklists according to the checked response of the questionnaire.

\subsection{Workshop 1}

The workshop was designed to explore, engage, and brainstorm the panelists in the first round [22]. As a step to begin the brainstorming process, the panelists were then provided with 10 possible standards criteria as given in Table 1 . These possible standards criteria were opened for group discussion and explanation, thus providing a chance for all experts to give their valuable ideas through comments in the workshop. The criteria were obtained after reviewing the available literature on environmentally friendly office. The experts were requested to give comments along with additional standard criteria which they considered relevant for the development of Green Office Standard in Thailand. These 10 possible standards criteria were developed from the expert panelist group consisting of experts from both the government and private organizations. The Department of Environmental Quality Promotion (DEQP) invited and recommended these experts. The panelists were further instructed to give their views in an open-ended questionnaire format on the need, transparency, and applicability of the abovestated standards criteria as well as the stability of the criteria about the standard.

Table 1

Green Office Standards Criteria of six countries

\begin{tabular}{|c|c|c|c|c|c|c|}
\hline & SP & HK & EN & $\mathbf{F}$ & USA & $\mathrm{TH}$ \\
\hline 1.Organization Awareness & $x$ & & & & & $x$ \\
\hline 2.Energy \& Other Resources & $x$ & $x$ & $x$ & $x$ & $\mathrm{x}$ & $x$ \\
\hline 3.Waste Management & $x$ & $x$ & $x$ & $x$ & $\mathrm{x}$ & $x$ \\
\hline 4. Indoor \& Outdoor Environment & $x$ & $x$ & & & & $x$ \\
\hline 5.Green Procurement & $x$ & $x$ & $x$ & $x$ & & $x$ \\
\hline 6.Continual Improvement & & & & & & $x$ \\
\hline 7.Staff communication/ Participation & & & $x$ & $x$ & & $x$ \\
\hline 8.Transportation \& Logistics & $x$ & & $x$ & $x$ & $x$ & $x$ \\
\hline 9.Water Resource & & & $x$ & $x$ & & $x$ \\
\hline 10.Building Design & & & & & & $x$ \\
\hline
\end{tabular}

\subsection{Workshop 2}

The second workshop was done as a follow-up process of the first workshop. Here in the second workshop, all the views, comments, criticisms of the expert panelists were compiled together and summarized to form the second checklists to define the standards criteria of Green Office in Thailand. The Green Office Standard in Thailand in the initial stage was formulated with ten categories as Energy Conservation, Communication and Participation, Waste Management and Reduction of Waste, 
Organization awareness, indoor and Outdoor Environmental Management, Green Procurement, Transportation and Logistics, Efficient Water Management, and Building Design.

\subsection{Workshop 3}

In the third workshop a checklist, prepared according to the critical views and comments from workshop 2, was administered to the panelists or participants. Later on, a standard was developed based on major agreement by retaining and revising the criteria made in the second round workshop. Further, it was improved and finally resulted in a Green Office Standard, Thailand based on the guidelines of the summarized criteria after taking into account major opinions and views of the panelists. The detail of the guidelines criteria included in this Standard is given in Table 2. These guidelines criteria were grouped into categories as follows:

1. Policies determination, operation planning, and continual improvement

2. Communication and creating awareness

3. Resource and energy consumption

4. Office waste management

5. Environment and safety

6. Eco-friendly procurement

\section{Results}

After making an assessment of ten pilot green offices and due to the contributions of the panel of environmental experts, criteria for the development of Green Offices are developed uniformly following the guidelines protocols of IS014001 Environmental management system, Greenhouse Gas Management, and Waste Minimization Pollution Prevention. This is developed in line with the views, opinions, and critical assessment of all environmental-related scholars, instructors, and participants in the three workshops of this research study. From the 3 workshops, following the EDFR technique, the panelists agreed to develop the Green Office Standard in Thailand after due consideration of the appropriate Environment Management objectives and guidelines criteria to achieve all-round environmental sustainability with the adoption of Green Office Standard in Thailand's Offices. A total of 6 categories, having one or more criteria, was ultimately developed (Table 2). 


\subsection{Environmental policy guidelines}

- should be approved by the chief executive or authorized person

- should specify policy announcement date

- authorized persons should explain the environmental aims and purposes of the office

- authorized persons should be involved in monitoring the compliance as environmental policy

1.1.1 Organization contexts and scopes of environmental management in the office

1.1.2 Environmental policies issues including the green office criteria for continual performance including:

- Improve environmental management system

- Minimize use of resources, waste generation, and GHG emission, switch to renewable energy to reduce pollution

- Follow laws and regulations of the Department of Environmental Quality Promotion (DEQP)

- Develop awareness to stakeholders

1.1.3 Plan annual green office operation by specifying work procedure details of all categories in writing after approval from the executive

1.1.4 Specify the target of energy usage indicators and waste generations including usages of electricity, fossil, water, paper, amount of waste generated, and GHGs emitted

\subsection{Environmental working group}

- Appoint a committee of staff of the office in written form with authorized signatures

- The appointed committee should represent each respective department and each selected member should have awareness of their responsibilities

\subsection{Resources and environmental issues specification}

This category includes the following indicators:

1.3.1 Specify and evaluate all office activities under the scope of green office certification such as:

- Compilation of all office activities

- Selection of a compassionate and responsible person

- Specify the amount of resource usage, including energy and generation of waste and pollution from each activity directly or indirectly from the office's daily activities

- Consideration of environmental issues and steps to be adopted in all situations, including during crisis or emergency

- Availability of environmental laws and regulations for these different situations

- Consideration of environmental issues as a top priority along with a scheduled timetable for review and evaluation on office resource usage at least once a year

- Specification of any additional activity if needed along with adjustment of scheduled plan activity

1.3.2 Analysis and solution of significant environmental issues as:

- Summarize the significant environmental issue

- Evaluate, provide manual, or guideline for solving the significant environmental issue and for office's work operation in both normal and emergency 


\subsection{Regulations and other related laws}

1.4.1 Collection of environmental laws and safety rules in office's- operation for framing guidelines as:

- Recruit a responsible person who has full knowledge of environmental laws

- Make a list of laws, covering the office's environmental issues and context

- specify other related laws and regulations on environmental issues

- Collect all latest laws, both international, national, and local laws, and review them at least once a year

1.4.2 Evaluate office's following environmental management laws and regulations as:

- A responsible legal officer should evaluate the office's environmental management consistent with laws and regulations

- The responsible legal officer should regularly check whether all office's operating procedure complies with laws and regulations

- If there is any inconsistency, it should be further investigated to find the cause and offer solution guidelines.

- Evaluation of following environmental laws should be conducted once a year

\subsection{GHGs information}

1.5.1 Collection of GHGs data from office activities consisting of:

- Electricity and fossil fuel energy consumption, water and paper usage, and waste generated

1.5.2 Check whether the minima target of GHGs quantity is achieved or unachieved

- If the target is achieved, the cause of it should be used as a conclusion for continual improvement

- If the target is unachieved, there should be cause analysis as well as finding an appropriate solution guideline along with systematic monitoring of the result

1.5.3 Investigate and inquire office staffs to find the proportion of GHGs emission as:

- Importance of reducing GHGs emission for developing the green office guideline for GHGs reduction

\subsection{Plan project for continual improvement}

1.6.1 Specify target objective for environmental project operation as:

- Plan Evaluation of specified objective target consistent with environmental policy, issue, and laws

- Plan Innovative activity that conformed to target environmental objective

- Plan appropriate duration of the project's operation

- Plan to recruit a responsible and knowledgeable person for the target project's operation

1.6.2 Provide project guidelines to achieve target objective for continual sustainable improvement

- Plan project operation and innovation for continual improvement

- Plan the frequency of project monitoring with a progress report

- Plan the project to finish at a scheduled time along with achieving the target objective

- Plan the unfinished project with a review to find a solution guideline

\subsection{Green office internal audit (for renewal agency)}




\subsubsection{Plan green office internal audit}

- Appoint internal auditors consisting of the head of an auditor and auditor who passed the green office operation training course and green office audit course

- Plan internal audit frequency at least once a year

- Plan a schedule to conduct an internal audit of all categories

- Plan to specify the internal auditor of each category

- Plan to complete all categories of internal audit

\subsection{Administrative review}

\subsubsection{Quorum determination for administrative review}

- Determine the executives to join the meeting, consisting of a representative of each department related to the operation of each category

- Determine the number of participants for a meeting which should be more than $75 \%$ of the green office committee with the signature of the participants as evidence of attendance

- Specify the reason for those absent committee members in the meeting with the recommendation

1.8.2 Determine meeting agenda and administrative review at least once in a year as:

- 1st agenda: operation tracking and improving the previous system

- 2nd agenda: environmental policy

- 3rd agenda: efficiency of a committee or environmental staff (sufficient and proper)

- 4th agenda: environmental operation tracking, communication and environmental opinion, law compliance, including development and solution guideline

- 5th agenda: changing to achieve efficient environmental operation

- 6th agenda: recommendation from the meeting and vision, executive's idea for continual green office operation

- Prepare a meeting report including figures of administrative review

Category 2: Communication and creating awareness

\subsection{Development of knowledge through training, and evaluation}

\subsubsection{Specify training plan, training operation, evaluation, and training record}

- Specify the detailed course and frequency of the training plan, including the importance of the green office, efficient usage of energy and other resources, pollution and waste management, green procurement, and GHGs emission

- Operate training according to the training plan and all trainees should attend more than $80 \%$ of each course

- Evaluate training through tests, examination, work performance along with a training report

2.1.2 Recruit a qualified and experienced person to conduct training for each course

\subsection{Campaign and publicize to employee}


2.2.1 A responsible man should campaign to inform the employee about environmental communication guidelines both external and internal office and also specify the topic of communication as given below:

- Environmental policy

- Significant environmental issues and management

- Law compliance

- Cleanliness and orderliness (5S)

- Target energy-resource measurement

- Target waste management measurement

- Resource, energy usage, GHGs, and waste generation

- Green goods and other service usages

- Specify the topic of communication widely in unlimited channel

- Specify the target receiver of the communication including both internal and external stakeholders

2.2.2 Establish channels to provide environmental recommendation/ ideas and improvement by following the guidelines:

- Establish channels for environmental recommendation or ideas in the form of QR Code and website

- Availability of a responsible man to provide recommendations/ ideas

- Prepare a list of environmental recommendation management to display on the public noticeboard

Category 3: Resource and energy consumption

\subsection{Water consumption}

3.1.1 Prepare a guideline for office water usage, by creating awareness to staff to save water in terms of time limitation, pattern and into changing innovative water-saving appliances and equipment

3.1.2 Prepare the data on water usage per unit and compare it with the target goal such as:

- Collect data to check the target goal achievement by collecting water usage data per month/per unit

- If the target goal is unachieved, investigate and summarize the cause with solution guidelines for continual improvement as there may be data variation in terms of the number of office staff, activities, or areas, etc.

3.1.3 Calculate percentage in compliance of water-saving measures in the working area by assessing personnel's behavior in that area

\subsection{Energy consumption}

3.2.1 Provide electricity usage guidelines for green offices as follows:

- Create awareness to save electricity

- Duration of usage and to put off the light during lunch hours or when not in the office

- Switch to using renewable energy and energy-saving appliances or equipment

3.2.2 Check whether the electricity usage data per unit achieve the target goal or not

- Collect electricity usage data in each month and per unit

- If achieved the target goal, summarize the cause for continual improvement

- If the target goal is unachieved, analyze the cause to provide a guideline as a solution

3.2.3 Calculate percentage in compliance as an electricity-saving measure in the working area by assessing personnel's behavior of the area 
3.2.4 Provide guidelines for fossil fuel as:

- Communication via electronic media

- Plan a trip or travel to the office in a bicycle or public transportation mode

3.2.5 Make a target goal of fossil fuel usage data per unit

- Check whether the goal is achieved or unachieved by collecting fossil fuel usage data per unit per month

- Summarize the cause leading to achievement for continual improvement

- In case the target goal is unachieved, there should be systematic analysis by collecting data on fossil fuel usage per month along with providing a solution guideline for continual improvement

\subsection{Other resource consumption}

3.3.1 Provide guidelines for paper usage guidelines for the office as follows:

- Create awareness in using paper to save resources

- Determine the pattern of paper usage

- Switch to e-files in place of printed documents

- Re-use paper such as printing on both sides of the paper if needed

3.3.2 Measure paper usage and provide an estimated target goal for paper usage data per unit and analyze whether the target goal is achieved or unachieved in the following ways:

- Collect paper usage data per unit each month

- If the target goal is achieved, analyze the cause for continual improvement

- If the target goal is unachieved, provide solution guidelines for improvement

3.3.4 Measure ink or stationery usage and provide a target goal guideline as follows:

- Creating awareness to save these resources and use them economically

- Determine the pattern of paper usage

- Switch to e-media instead of printed documents

3.3.5 Prepare percentage of compliance in ink, stationery, and office equipment usage and saving measures in the working area

\subsection{Meeting and exhibition}

3.4.1 Prepare a percentage of e-communication and meeting information delivery, namely, QR Code, Email, Social network, Intranet, etc.

3.4.2 Meeting and exhibition should be arranged using eco-friendly materials to reduce energy consumption, and waste generation as follows:

- Arrange a suitable size meeting room in proportion to the participants

- Decoration or exhibition of meeting room area should not use low quality, degradable sub-quality standard

- Provide guidelines specifications for eco-friendly external office

- Switch to using e-media instead of using paper and ink to reduce wastage

- Prepare eco-friendly food and beverage for catering participants

\subsection{Waste management}

Page 11/18 
4.1.1 Prepare appropriate operation guidelines for sorting, collecting, and disposal of waste as follows:

- Different type of waste bin should sort into different labels and placed them suitably at various working areas at every spot

- The waste should be inspected to specify the type of waste in every trash

- Different departments should have a suitable wastes collection point

- Should have a proper waste dumping in every point for inspection randomly

- Every local authority or contractor should regularly manage and inspect the waste generated

4.1.2 Waste recycling for reuse to reduce the quantity of waste generated for disposal

- There should be systematic sorting to reuse the waste

- Should record the data of generated waste per month

- Comparative analysis should be done to check whether the target waste of disposing of the least quantity of waste is achieved or not along with investigating the cause with a solution guideline

\subsection{Wastewater management}

4.2.1 Provide guidelines for offices' wastewater management and wastewater quality maintenance by following the relevant standards as follows:

- Recruit a responsible and qualified knowledgeable person to manage the wastewater

- Apply efficient and suitable wastewater treatment such as food scrap screening, using grease trap, or suitable wastewater treatment system and other wastewater components

- There should be wastewater treatment at every point to help in releasing wastewater

- Wastewater quality should be checked to observe whether the result meets the quality of a standardized law

4.2.2 Provide wastewater treatment and equipment maintenance guidelines as follows:

- Use different forms of wastewater treatment and maintenance as scooping, cleaning, and screening food scraps or grease trap in a specified frequency with providing data in terms of quantity and contamination

- Eliminate sludge/ food scraps/ oil and grease through the wastewater treatment system

- Inspect for leakage, improve, repair wastewater treatment system for usability, efficiency and to remove contamination with other sources

Category 5: Environment and Safety in the office

5.1 Air in the office

5.1.1 Control air pollution in the office in the following ways:

- There should be a technician to perform maintenance service of air conditioner, copying machines, printer, etc.

- Recruit a responsible person to perform the job of daily maintenance

- Prepare a plan for maintenance

- Maintenance person should take care to control air pollution and $\mathrm{CO}_{2}$ emission in the office 
5.1.2 Campaign for 'No smoking'. Specify smoking area for office personal or visitors

- Promote no smoking campaigns

- Smoking zone and the smoking prohibited areas should be displayed with symbols

- The smoking zone should be located in an open space, and not near the office entrance exit to protect the health of non-smokers.

5.1.3 Air pollution management during construction or repairing of an office building

- Provide guidelines to control air pollution during an office renovation, construction, repairing

- Provide a reserved area for the employee to prevent them from air pollution effect

- Place a notification sign at the construction or repairing site to prevent danger or entry

\subsection{Lightning in the office}

5.2.1 Guidelines for measuring light intensity and operation as:

- Lightning equipment such as electric bulbs and its usage should be measured

- The light meter should have a standard

- Measurement results should conform to the calibrated standard

- There should be a regular inspection to check its performance according to the standard

- A responsible person should be recruited as an inspector to look after it.

\subsection{Noise in the office}

\subsubsection{Provide guidelines for noise pollution control in the office building as:}

- Specify the supporting measure for noise pollution management inside the office

- Measure to check whether it is performing in compliance with the specified standard to prevent noise pollution inside the office

5.3.2 Noise pollution management during office's construction building or repairs that may affect the health of an employee

- Provide a supporting guideline for managing noise pollution during offices' construction or repairing

- Measure to check performance in compliance with the specified standard inside the office

- Place a notification sign at the construction or repairing site to prevent danger or entry restriction

\subsection{Livability in the office}

5.4.1 Provide livability management standard of the office's operations as follows:

- Prepare an internal and external diagram of the office building with a specification of details

- Specify appropriately the functions of specific zone of both internal and external parts of the office building

- Specify the time for cleaning and repairing both inside and outside the building (specific area and general area)

- Provide plan target goal to increase the green area of the office

5.4.2 Provide the percentage of the usable area according to the objectives of the office

5.4.3 Provide percentage of various area that needs maintenance

5.4.4 Provide guidelines for controlling vector animals in the office as:

- Trace and track the carrier of vector animals at least once a month

- Provide guidelines to manage when the carriers are traced

Page 13/18 


\subsection{Emergency readiness}

5.5.1 Training of firefighters and evacuation plan

- Provide a training plan for firefighters and evacuation

- $40 \%$ of all office employees should receive training for fighting fire outbreaks and emergency measures of evacuation

- All employees must participate in fire evacuation training at least 1 time per year

- Training participants should be provided a certificate as evidence for joining the course

- All employees should be informed clearly of the signs of emergency exits and the escape routes

5.5.2 There should be an appropriate emergency plan. At least 4 persons in an office should be trained to inform the employee of the emergency plan

5.5.3 There should be sufficient firefighting equipment and alarm system in the office with readiness to use in an emergency.

- At least four persons in an office should be trained on how to use, install and inspect firefighting equipment and fire alarm system

\section{Category 6: Eco-friendly procurement}

\subsection{Procurement and employment}

\subsubsection{Eco-friendly procurement}

- Recruit a responsible person who understands eco-friendly procurement

- Search a list of eco-friendly goods along with the detailed source

- Make a list of eco-friendly products that are consistent with the actual products used in the office

- Notify the seller/supplier for cooperation in ordering eco-friendly products.

6.1.2 Calculate the percentage of eco-friendly materials procured in the office

Note: Percentage of eco-friendly procurement will be compared to the quantity of purchasing and/or products value as:

- Make a list to display the procured office materials and specify them by brand and model of products

- Make a list to display the green label of products

- Calculate the percentage of eco-friendly products from the displayed list of products in terms of quantity and value

\subsection{Employment}

6.2.1 Percentage of agency employment or the eco-friendly person

- Provide a certified environmental standard of agency as evidence of following eco-friendly standard

- If the agency/office has no certified environmental standard, it must apply for a preliminary environmental evaluation from a certifying agency

- There should be an environmental contract or agreement when the employee practice in the office

- Selected agency or person should be trained to know the green office and environmental management guidelines consistent with their activities

- The certifying agency or person can explain the environmental management guideline consistent with their offices' activities 
6.2.2 Percentage of environmental care on inspection of an office's operator/ employee working area

Note:

- In case of hiring as a full-time employee, he or she must be evaluated at least 1 time per month

- In case of hiring as a part-time employee, he or she must be evaluated always when they come to operate in the office

6.2.3 Percentage of eco-friendly service selection (outside the office) such as hotel, venues, or other places that have been registered as eco-friendly places

Note:

- Make a list of procured goods or places that were certified as eco-friendly standards such as ISO 14001, Green hotel, Green label, etc.

- If the meeting places are not certified as eco-friendly places, need to select some places that can save time in traveling and arrangement of the meeting to make the selected venues as Green sustainable meeting areas.

From the three workshops, the researchers gained numerous insights from the panelists' comments relating to the visibility, requisite, and inclusion criteria for the development of the Green Office Standard along with the role of the categories and its guidelines criteria. For instance, during the 2nd workshop, a panelist commented to include a criterion to explain the Environment Quality Indoor and Outdoor standard as outlined by WWF Green Office Guidelines. The critical views of the panelists indeed help to the creation of guidelines and manuals leading to Green Office Standard implementation. Another panelist indicated: "I believe the standards to have a good job. Many indicators criteria are included similarly as in carbon footprint assessment calculation". From the above result, it can be stated that the development of the green office standards passes through three major stages of lifecycle process as 1) organizing the responsible committee, 2) review of previous studies and outlining the pre-standard, and 3) development of the standard. This article explains guidelines criteria for Green Office management standards which can be grouped into six categories, having a specific weight percentage as shown in Table 2. From the above guidelines criteria, the rating will be considered relying on the attribution of the area, environmental consideration and practices, office staff's knowledge and awareness, the quantity of greenhouse gas emitted, and reduction in the office. The assessment criteria of all sub-criteria are provided to the committee asking them to select a rating from the 5 levels marked as $1-5$.

\section{Conclusion And Discussions}

Criteria for the development of the Green Office will help to promote offices to perform daily office work operation procedures with environmental awareness and taking responsibility to save energy, minimize resource usage, reduce and reuse waste for developing into a sustainable environment. So, the Green Office is a Management Standard Organizations that focus on the ecological objectives of minimizing carbon footprint or retarding the emission of $\mathrm{CO}_{2}$ to develop a sustainable environment, by following the above-noted guidelines criteria. The Green Office Standard manages the systematic improvement of offices' environmental performance. The impact of climate change can be felt in all parts of the world and all organizations, both private as well private are responsible to take steps to perform offices' activities and work performance with the due conformation of the guidelines criteria of Green Office Management Standard. Following the norms of these Standard guidelines criteria in office work procedures will help to create an eco-friendly green sustainable environment for the future world. In this regard, mention can be made of the attempts, guidance, and roles of pioneer contributors in its development in Thailand such as the Faculty of Environment and Resource Studies, Thailand under the assistance of the DEQP. With their hard work utmost dedication and contribution, Green Office Management Standard was developed including guideline criteria to be followed to help in certifying the participating organization as the Green Office Standard Recipient after completing the procedure of evaluation that follows the stated Green Office guidelines criteria. In this way, such a certified office achieved the Green Office Standard to be an environmentally friendly organization in Thailand. Some of the guidelines criteria that need to be followed to be a certified Green Office can be grouped into six categories:

1. Policies determination, operation planning, and continual improvement

2. Communication and creating awareness 
3. Resource and energy consumption

4. Office waste management

5. Environment and safety

6. Eco-friendly procurement

Even though the status of the Green Office Standard in Thailand is in the nascent stage as a step to mitigate climate change by reducing the office's ecological footprint, it has improved in environmental friendly work process through training and assessment of certified green offices. Development of green offices are essential for promoting sustainable lifestyles and efficient environmental management in the offices. However, the accomplishment of the Green Office Management Standard for environmental sustainability needs consideration on other variables, including the obligation and understanding of office personals at various strata, positions, and roles and responsibilities in the office organization, from top to bottom. However, different standards have different environmental obligations, including producers' expectations, and consumers buying power, so quite often the environmental issues are blended into the corporate culture to solve business cost and profit aspects. Also it depends on each department's responsibilities level to minimize global environmental degradation while conserving the world's bio-diversity. Subsequently, assessment of ten sample organizations was conducted in the middle month of 2016, targeting to train all the office staffs of different strata from top to bottom of the organization hierarchy, to bring awareness of the criteria guidelines, and protocol for using eco-friendly tools and equipment at their offices. Environmental experts that were included in the assessment team contributed immensely to effectively adopt environmentally friendly skills. For developing reliability and validity to this office practice for environmental sustainability, organizations' members must perform office work processes as per guidelines of eco-friendly guidelines criteria of green offices and their services should be self-evaluated or, by co-workers and upright professionals rather than being evaluated externally. On the whole, successful environmentally friendly management depends on the behavior of the organization team, in terms of following the accurate guidelines criteria. However, Green Office Management Standard in different settings may varies, as each offices has certain legal compliance. Therefore, it can be suggested that commitment to compliance and utilization of existing technologies will help to increase environmental management efficiencies to satisfy the specific need of the organization.

\section{Declarations}

1. Availability of data and materials

Not Applicable

2. Competing interests

The authors declare that there is no conflict of interest. Informed consent was obtained from all participants included in the study.

\section{Funding}

Not Applicable

\section{Author's contributions}

Sayam Aroonsrimorakot was the head and applicant of the research project.

Meena Laiphrakpam was responsible for analyzing, writing and presenting in English.

Kornkanok Sarapirom was responsible for collecting, analyzing and presenting the data in Thai.

\section{Acknowledgements}

The authors would like to thank the Department of Environmental Quality Promotion and Mahidol University for supporting this research project. The authors also were thankful to all experts and participants for sparing their valuable time in participating the 
research evaluation and assessment.

6. Authors' information (optional)

Given in the title page.

\section{References}

1. WWF. What is the green office? World Wide Fund for Nature Finland, 2016. Available at: https://wwf.fi/en/green-office/whatis-green-office

2. Aroonsrimorakot S, Laiphrakpam M, Paisantanakij W. Impacts of Green Office Projects in Thailand: An Evaluation Consistent with Sustainable Development Goals (SDGs). J Sustain Dev (JSD). 2020; 13(4): 164-177.

3. Aroonsrimorakot S, Laiphrakpam M, Korattana C. Green office, its features and importance for sustainable environmental management: A comparative review in search for similarities and differences. Journal of Thai Interdisciplinary Research. 2019; 14(5): 31-38.

4. Chowdhury AH, Mohammad N, Haque MRU, Hossain T. Developing 3Rs (Reduce, Reuse and Recycle) strategy for waste management in the urban areas of Bangladesh: Socioeconomic and climate adoption mitigation option. IOSR Journal of Environmental Science, Toxicology and Food Technology (IOSR-JESTFT). 2014; 8(5): 9-18.

5. Scafetta N. Climate change and its causes, a discussion about some key issues. arXiv preprint arXiv. 2010; 1003.1554, March 8.

6. Sodangi IA, Izge AU, Maina YT. Climate change: causes and effects on African agriculture. 2011; Available at: http://hdl.handle.net/123456789/188.

7. Wichai-utcha N, Chavalparit O. 3Rs Policy and plastic waste management in Thailand. Journal of Material Cycles and Waste Management. 2019; 21(1): 10-22.

8. Aroonsrimorakot S. Green Office Management Standard in Mahidol University, Thailand. Pertanika Journal of Social Sciences \& Humanities. 2018; 26(4): 2505-2521.

9. WWF. Green Office Environmental Management System for Sustainable Organisations, Achievements, and Activities in 2010. (p.5). World Wildlife Fund. Available at: https://wwf.fi/mediabank/1414.pdf.

10. Aroonsrimorakot S, Phuynongpho S. Factors affecting the water usage performance of the standard application of green office in Thailand. Journal of Thai Interdisciplinary Research. 2017; 12(2): 24-30.

11. Varanavicius V, Navikaite A. Competitive advantage attainment via synergy in green offices. Journal of International Studies, 2015, 8(3): 141-151. DOI: 10.14254/2071-8330.2015/8-3/11

12. WGBC. The benefits of green buildings. World Green Building Council. 2016; Available at: https://www.worldgbc.org/benefits-green-buildings

13. HKGBC. Hong Kong Green Office Guide. Hong Kong Green Building Council. 2016; Available at: https://www.hkgbc.org.hk/eng/engagement/guidebooks/green-office-guide/index.jsp.

14. WWF. Green Office Environmental Management System. World Wide Fund for Nature Finland. 2017; Available at: https://wwf.fi/app/uploads/v/7/4/ewdqmnvemxnzhxmjpotrczf/go_valmis_presentation_2017_pakattu_220_oikeaversio.pdf

15. Phatthana CP. Future research with EDFR. Journal of Educational Administration Khon-Kaen University. 2005; 1(2): 19-31.

16. Poolpatarachewin C. Ethnographic Delphi futures research. Journal of Research Methodology. 2015; 1(2): 16-23. Available at: https://portal.edu.chula.ac.th/pub/jrm/index.php/jrm/article/viewFile/30/pdf_21

17. Palmer C. Ethnography: a research method in practice. International journal of tourism research, 2001; 3(4): 301-312.

18. Byrne M. Ethnography as a qualitative research method. AORN Journal. 2001; 74(1): 82-82.

19. Genzuk M. A synthesis of ethnographic research. Los Angeles, CA: Metropolitan Project/ARCO Foundation. 1999; Available at: https://web-app.usc.edu/web/rossier/publications/33/Ethnographic_Research.pdf

20. Hammersley M. Reading ethnographic research: a critical guide (2nd ed.). 1998; London; New York: Longman.

Page $17 / 18$ 
21. Van Maanen J. Ethnography In: Kuper, A., Kuper, J. (Eds.) The Social Science Encyclopedia (2nd ed. 1996; 263-265). London: Routledge.

22. Textor RB. The ethnographic futures research method: An application to Thailand. Futures. 1995; 27(4): 461-471.

23. Hirschhorn F. Reflections on the application of the Delphi method: lessons from a case in public transport research. International Journal of Social Research Methodology. 2019; 22(3): 309-322.

24. Hirschhorn F, Veeneman W, van de Velde D. Inventory and rating of performance indicators and organisational features in metropolitan public transport: A worldwide Delphi survey. Research in Transportation Economics. 2018; 69:144-156.

25. von der Gracht H. Consensus measurement in Delphi studies. Review and implications for future quality assurance. Technology Forecasting and Social Change. 2012; 79(8): 1525-1536.

26. Dalkey N, Helmer O. An experimental application of the Delphi method to the use of experts. Management Science. 1963; 9(3): 458-467. Available at: ocsci2.ucsd.edu/ aronatas/project/academic/delphi method of convergence.pdf

27. Beech BF. Changes: The Delphi technique adapted for classroom evaluation of clinical placements. Nurse Education Today. 1991; 11(3): 207-212.

28. Williams PL, Webb C. The Delphi technique: a methodological discussion. Journal of advanced nursing. 1994; 19(1): 180186. https://doi.org/10.1111/j.1365-2648.1994.tb01066.x

29. Reid N. The Delphi technique: its contribution to the evaluation of professional practice. Professional competence and quality assurance in the caring professions. 1988; 230:262.

30. de Meyrick J. The Delphi method and health research. Health education. 2003; 103(1): 7-16.

31. Turoff M, Linstone HA. The Delphi method-techniques and applications. 2002.

32. Passig D. Imen-Delphi: A Delphi variant procedure for emergence. Human Organization. 1997; 56(1): 53-63. 